\title{
Repression of IGF-I-induced osteoblast migration by (-)-epigallocatechin gallate through p44/p42 MAP kinase signaling
}

\author{
TETSU KAWABATA ${ }^{1-3}$, HARUHIKO TOKUDA ${ }^{2,4}$, GO SAKAI ${ }^{1,2}$, KAZUHIKO FUJITA ${ }^{1,2}$, \\ RIE MATSUSHIMA-NISHIWAKI ${ }^{2}$, TAKANOBU OTSUKA ${ }^{1}$ and OSAMU KOZAWA ${ }^{2}$
}

\author{
${ }^{1}$ Department of Orthopedic Surgery, Nagoya City University Graduate School of Medical Sciences, Nagoya, Aichi 467-8601; \\ ${ }^{2}$ Department of Pharmacology, Gifu University Graduate School of Medicine, Gifu 501-1194; \\ ${ }^{3}$ Department of Orthopedic Surgery, Toyokawa City Hospital, Toyokawa, Aichi 442-8561; \\ ${ }^{4}$ Department of Clinical Laboratory, National Center for Geriatrics and Gerontology, Obu, Aichi 474-8511, Japan
}

Received April 16, 2018; Accepted July 7, 2018

DOI: $10.3892 /$ br.2018.1140

\begin{abstract}
Polyphenolic compounds in beverages may have benefits in the prevention of osteoporosis. It has been demonstrated previously that insulin-like growth factor-I (IGF-I) could stimulate the migration of osteoblasts. In the present study, it was investigated whether chlorogenic acid, a major polyphenol in coffee, and (-)-epigallocatechin gallate (EGCG), a major polyphenol in green tea, could affect this IGF-I-stimulated migration of osteoblast-like MC3T3-E1 cells. The IGF-I-stimulated osteoblast migration, evaluated by Transwell cell migration and wound-healing assays, was inhibited by EGCG but not chlorogenic acid. IGF-I induced the phosphorylation of p44/p42 mitogen-activated protein (MAP) kinase, p70 S6 kinase and Akt. The IGF-I-induced migration was suppressed by PD98059, a MAP kinase kinase 1/2 inhibitor, and deguelin, an Akt inhibitor, but not rapamycin, an inhibitor of the upstream kinase of p70 S6 kinase (mammalian target of rapamycin). EGCG attenuated the IGF-I-induced phosphorylation of p44/p42 MAP kinase but not Akt. Taken together, the present results suggest that EGCG inhibits IGF-I-induced osteoblast migration via p44/p42 MAP kinase.
\end{abstract}

\section{Introduction}

Bone tissue is consistently regenerated through a sequential process of bone resorption and bone formation termed bone remodeling $(1,2)$. Bone resorption is conducted by osteoclasts and bone formation is performed by osteoblasts $(1,2)$. The process of bone remodeling is initiated with osteoclastic bone resorption, following bone formation executed by osteoblasts

Correspondence to: Professor Osamu Kozawa, Department of Pharmacology, Gifu University Graduate School of Medicine, 1-1 Yanagido, Gifu 501-1194, Japan

E-mail: okkasugai@yahoo.co.jp

Key words: osteoblast, migration, catechin, insulin-like growth factor-I, chlorogenic acid, p44/p42 mitogen-activated protein kinase which migrate to the resorbed sites $(1,2)$. Appropriate bone quality and quantity, which is strictly regulated by various hormones, cytokines and growth factors, is maintained by the orchestrated cooperation of osteoclasts and osteoblasts (2). Thus, it is considered that impairment of bone remodeling causes metabolic bone disease mostly represented by osteoporosis (2). Furthermore, accumulating data indicates that osteoblast migration serves crucial roles not only in many processes of physiological bone metabolism but also in pathological bone processes including bone-fracture healing $(1,3-5)$. However, the exact mechanism for this involvement of osteoblast migration remains unclear.

It is generally recognized that insulin-like growth factor-I (IGF-I) serves pivotal roles in the regulation of growth and bone metabolism $(6,7)$. In our previous studies $(8,9)$, it was demonstrated that IGF-I stimulates the activity of alkaline phosphatase, a biomarker of bone formation, through the activation of $\mathrm{p} 44 / \mathrm{p} 42$ mitogen-activated protein (MAP) kinase and phosphatidylinositol 3-kinase/Akt in osteoblastlike MC3T3-E1 cells. Regarding the effect of IGF-I on osteoblast migration, it has been reported that IGF-I secreted from osteoblast-like MC3T3-E1 cells acts as a chemotactic factor for these cells through Akt activation (10). However, the mechanism for how IGF-I induces the migration of osteoblasts remains to be fully elucidated.

Natural polyphenolic compounds contained in beverages possess various beneficial properties including anti-oxidative and anti-inflammatory effects $(11,12)$. Among these compounds, it is established that chlorogenic acid is a main phenolic compound in coffee while (-)-epigallocatechin gallate (EGCG) is a major polyphenol in green tea (13-15). Regarding the effects of chlorogenic acid on bone, it has been documented that chlorogenic acid may strengthen the femoral diaphysis against mechanical stress due to upregulation of mineralization in the tibia (16). In addition, chlorogenic acid reportedly inhibits osteoclast functions, resulting in the suppression of bone resorption (17). Accumulating data indicates that green tea consumption in elderly subjects decreases the risk of bone fracture by increasing bone mass and mineral density (18). It has further been reported that EGCG may inhibit osteoclastic bone resorption and stimulate osteoblastic 
bone formation $(18,19)$. In our previous study $(20)$, it was identified that EGCG enhanced osteoprotegerin synthesis in osteoblast-like MC3T3-E1 cells. However, the exact roles of chlorogenic acid and EGCG in bone metabolism are yet to be fully clarified.

In the present study, using Transwell migration and woundhealing assays, the effects of chlorogenic acid and EGCG on the IGF-I-induced migration of osteoblast-like MC3T3-E1 cells were investigated. Additionally the mechanism underlying IGF-I-induced migration was examined by western blot analysis, and the effects of corresponding inhibitors (PD98059, rapamycin and deguelin) on migration were evaluated.

\section{Materials and methods}

Materials. IGF-I was obtained from R\&D Systems, Inc. (Minneapolis, MN, USA). Chlorogenic acid and EGCG were purchased from Sigma-Aldrich (Merck KGaA, Darmstadt, Germany). PD98059, rapamycin and deguelin were obtained from Calbiochem-Novabiochem Corporation (San Diego, CA, USA). Phospho-specific p44/p42 MAP kinase antibody (cat. no. 9101), p44/p42 MAP kinase antibody (cat. no. 9102), phospho-specific p38 MAP kinase antibody (cat. no. 4511), phospho-specific stress-activated protein kinases (SAPK)/ c-Jun N-terminal kinase (JNK) antibody (cat. no. 9251), phospho-specific p70 S6 kinase antibody (cat. no. 9205), phospho-specific Akt antibody (cat. no. 9275) and Akt antibody (cat. no. 9272) were purchased from Cell Signaling Technology (Danvers, MA, USA). GAPDH antibody (cat. no. SC-47724) was obtained from Santa Cruz Biotechnology, Inc. (Dallas, TX, USA). An electrochemiluminescence (ECL) western blotting detection system was purchased from GE Healthcare (Amersham, UK). Other materials and chemicals were obtained from commercial sources. Chlorogenic acid was dissolved in ethanol. EGCG was dissolved in dimethyl sulfoxide. The maximum concentration of ethanol or dimethyl sulfoxide was $0.1 \%$, which did not affect the assay for cell migration or western blot analysis in preliminary experiments.

Cell culture. Cloned osteoblast-like MC3T3-E1 cells derived from newborn mouse calvaria (21) were provided by Dr Masayoshi Kumegawa (Meikai University, Sakado, Japan) and maintained as previously described (22). Briefly, MC3T3-E1 cells were cultured in $\alpha$-minimum essential medium ( $\alpha$-MEM) containing 10\% fetal bovine serum (FBS) at $37^{\circ} \mathrm{C}$ in a humidified atmosphere of $5 \% \mathrm{CO}_{2} / 95 \%$ air. The cells were seeded into $90-\mathrm{mm}$ diameter dishes $\left(2 \times 10^{5}\right.$ cells/dish) in the $\alpha$-MEM containing $10 \% \mathrm{FBS}$ for 5 days. The medium was then exchanged for $\alpha$-MEM containing $0.3 \% \mathrm{FBS}$, and the cells were subsequently used for western blot analysis after $48 \mathrm{~h}$ culture at $37^{\circ} \mathrm{C}$. For the cell migration assay, MC3T3-E1 cells in $\alpha$-MEM containing $10 \%$ FBS cultured for 3 days were sub-cultured in $\alpha$-MEM containing $0.3 \% \mathrm{FBS}$ for $6 \mathrm{~h}$ (all at $37^{\circ} \mathrm{C}$ ), and then were used for the migration experiments.

Cell migration assay. A Transwell cell migration assay was performed using a Boyden chamber (polycarbonate membrane with $8-\mu$ m pores; Corning Inc., Corning, NY, USA) as described previously (23). In brief, MC3T3-E1 cells were trypsinized and seeded $\left(1.0 \times 10^{5}\right.$ cells/well) onto the upper chamber in $\alpha$-MEM containing $0.3 \%$ FBS. IGF-I ( 0 or $10 \mathrm{nM})$ was added to the lower chamber in $\alpha$-MEM containing $0.3 \% \mathrm{FBS}$ and incubated for $16 \mathrm{~h}$ at $37^{\circ} \mathrm{C}$, and the cells on the upper surface of the membrane were then mechanically removed. The migrated cells adherent to the underside of the membrane were fixed with $4 \%$ paraformaldehyde and stained with DAPI solution. The migrated cells were photographed and quantified using fluorescent microscopy at a magnification of $\mathrm{x} 20$ by counting the stained cells in three randomly selected fields. Prior to assays, subsets of cells were pretreated with chlorogenic acid $(0,10,30$ or $50 \mu \mathrm{M})$, EGCG $(0,0.1,0.3$ or $1.0 \mu \mathrm{M})$, PD98059 $(0$ or $30 \mu \mathrm{M})$, rapamycin $(0$ or $50 \mathrm{ng} / \mathrm{ml})$ or deguelin $(0$ or $0.5 \mu \mathrm{M})$ for $60 \mathrm{~min}$ at $37^{\circ} \mathrm{C}$.

For a wound-healing assay, MC3T3-E1 cells were seeded in $\alpha$-MEM containing $10 \%$ FBS at $1.0 \times 10^{5}$ cells/well into an ibidi Culture-Insert 2 Well (ibidi GmbH, Martinsried, Germany) with a $500-\mu \mathrm{m}$ margin from the side of the well and grown for $24 \mathrm{~h}$ at $37^{\circ} \mathrm{C}$. Following removal of the insert, the cells were stimulated with $70 \mathrm{nM}$ IGF-I or vehicle (phosphate-buffered saline supplemented with $0.01 \%$ bovine serum albumin) for $8 \mathrm{~h}$ at $37^{\circ} \mathrm{C}$. Based on results of the Transwell assays, subsets of control and stimulated cells were pretreated with $1 \mu \mathrm{M}$ EGCG or vehicle for $60 \mathrm{~min}$. The cells were photographed using an EOS Kiss X4 digital camera (Canon Inc., Tokyo, Japan) connected to a CK40 culture microscope (Olympus Co., Ltd., Tokyo, Japan) prior to the stimulation with IGF-I and after $8 \mathrm{~h}$. The area comprised of migrated cells was measured by ImageJ software (version 1.48; National Institutes of Health, Bethesda, MD, USA).

Western blot analysis. MC3T3-E1 cells pretreated with the stated doses of EGCG, PD98059, rapamycin, deguelin or vehicle, then stimulated by $10 \mathrm{nM}$ IGF-I or vehicle in $1 \mathrm{ml}$ $\alpha$-MEM containing $0.3 \%$ FBS for different time periods (1, 3, $5,10,15,20$ and $30 \mathrm{~min}$ ) at $37^{\circ} \mathrm{C}$. The cells were then lysed, homogenized and sonicated in a lysis buffer containing $62.5 \mathrm{mM}$ Tris/ $\mathrm{HCl}, \mathrm{pH}$ 6.8, 2\% sodium dodecyl sulfate (SDS), $50 \mathrm{mM}$ dithiothreitol and $10 \%$ glycerol. SDS-polyacrylamide gel electrophoresis (PAGE) was performed according to the method of Laemmli (24) on $10 \%$ polyacrylamide gels. The protein was fractionated and transferred onto an Immun-Blot polyvinylidene difluoride (PVDF) membrane (Bio-Rad Laboratories, Inc., Hercules, CA, USA). The membranes were blocked at $4^{\circ} \mathrm{C}$ with $5 \%$ fat-free dry milk in Tris-buffered saline-Tween (TBS-T; $20 \mathrm{mM}$ Tris/HCl, pH 7.6, $137 \mathrm{mM} \mathrm{NaCl}, 0.1 \%$ Tween-20) for $1 \mathrm{~h}$ prior to incubation with primary antibodies. Western blot analysis was performed as described previously (25) using the phospho-specific p44/p42 MAP kinase, p44/p42 MAP kinase, phospho-specific p38 MAP kinase, phospho-specific SAPK/JNK, phospho-specific p70 S6 kinase, phospho-specific Akt, Akt and GAPDH (loading control) antibodies as primary antibodies, and peroxidase-labeled antibodies raised in goat against rabbit immunoglobulin G (cat. no. 5110-0336; KPL, Inc., Gaithersburg, MD, USA) used as secondary antibodies. The primary and secondary antibodies were diluted at 1:1,000 with 5\% fat-free dry milk in TBS-T and incubated at room temperature. The peroxidase activity on the PVDF membrane was visualized on X-ray film by means of the ECL western blotting detection system. 


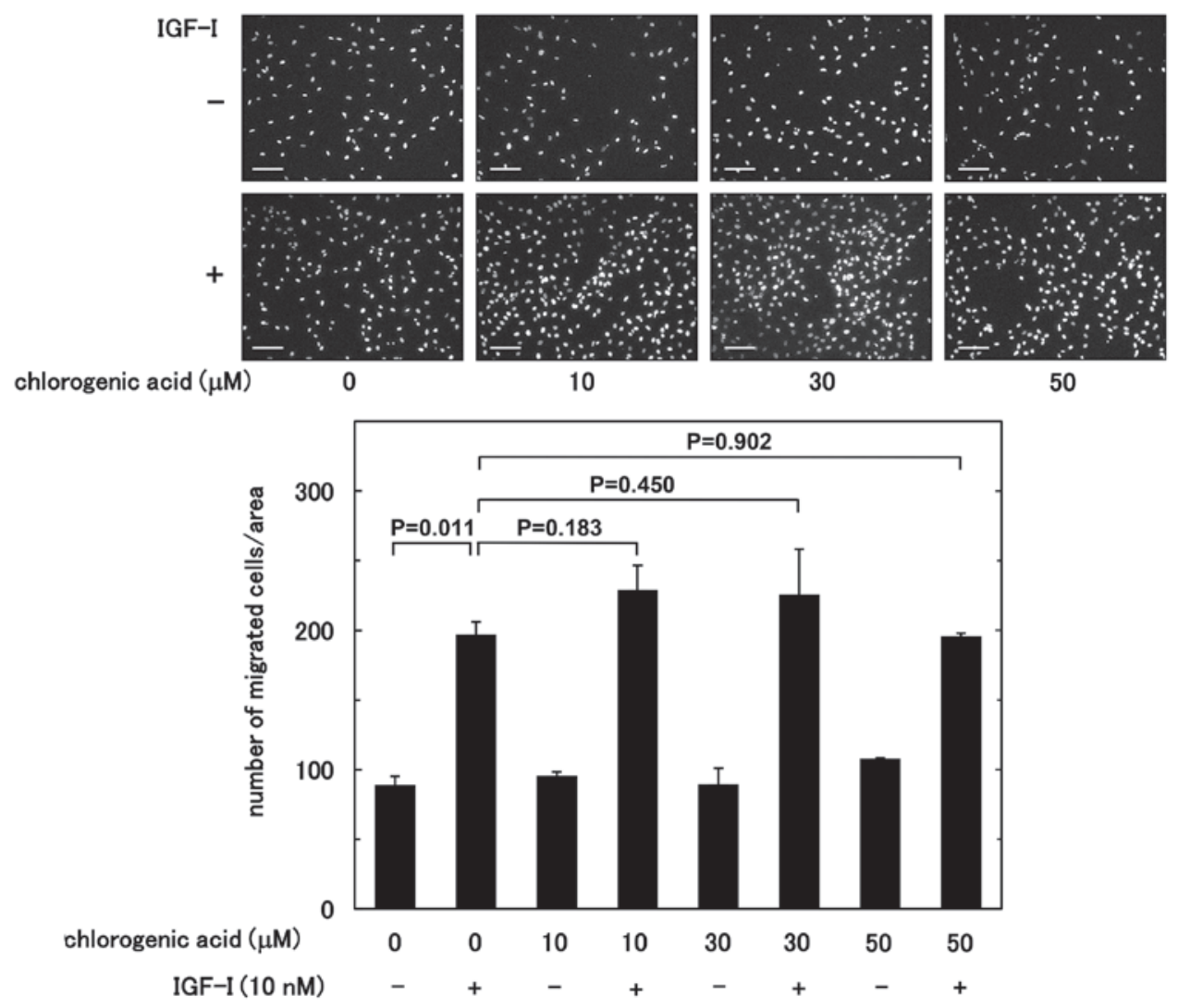

Figure 1. Effect of chlorogenic acid on IGF-I-induced migration of MC3T3-E1 cells. Cell migration was evaluated using a Boyden chamber. The cells were pretreated with various doses of chlorogenic acid for $60 \mathrm{~min}$, and then stimulated by $10 \mathrm{nM}$ IGF-I or vehicle for $16 \mathrm{~h}$. Photographs (white signal) and a histogram showing the numbers of migrated cells in each panel are presented. Magnification, x20; scale bars, $100 \mu \mathrm{m}$. IGF-I, insulin-like growth factor-I.

Densitometric analysis. Densitometric analysis was performed using a scanner and ImageJ version 1.48. The levels of phosphorylated target proteins were calculated as follows: the background-subtracted signal intensity of each phosphorylation signal was respectively normalized to the total protein signal, and plotted as a fold increase in comparison to that of the control cells treated without pretreatment or stimulation.

Statistical analysis. The data were analyzed by one-way analysis of variance followed by the Bonferroni method for multiple comparisons between pairs, and $\mathrm{P}<0.05$ was considered to indicate statistical significance. Microsoft Excel 2010 (Microsoft Corporation, Redmond, WA, USA) was used for the analysis. All data are presented as the mean \pm standard error of the mean of triplicate determinations from three independent cell preparations.

\section{Results}

Effects of chlorogenic acid and EGCG on IGF-I-induced migration of MC3T3-E1 cells. It has been reported that IGF-I induces the migration of osteoblasts including osteoblast-like MC3T3-E1 cells (10). The present study identified that IGF-I elicited the migration of MC3T3-E1 cells when assessed by Transwell and wound healing assays. In the Transwell assay, the effect of IGF-I on cell migration was dose-dependent over the range 3-30 $\mathrm{nM}$, whereas in the wound healing assay, the effect was dose-dependent over the range 1-100 nM (data not shown).
Initially, the effect of chlorogenic acid or EGCG on the IGF-I-induced migration of MC3T3-E1 cells was investigated using a Boyden chamber. Chlorogenic acid had no significant effect on the IGF-I-stimulated migration up to $50 \mu \mathrm{M}$ (Fig. 1). By contrast, the IGF-I-stimulated migration was suppressed by EGCG in an apparent dose-dependent manner in the range 0.1-1.0 $\mu \mathrm{M}$; with the concentrations 0.3 and $1.0 \mu \mathrm{M}$ yielding significant effect ( $\mathrm{P}=3.0 \times 10^{-4}$ and $2.5 \times 10^{-4}$, respectively) (Fig. 2).

The effect of EGCG on the IGF-I-stimulated migration of osteoblast-like MC3T3-E1 cells was subsequently evaluated by wound-healing assay. As above, EGCG $(1 \mu \mathrm{M})$ markedly suppressed the IGF-I-stimulated MC3T3-E1 cell migration $(\mathrm{P}=0.020)$ (Fig. 3).

Effect of IGF-I on the phosphorylation of p44/p42 MAP kinase, 38 MAP kinase, SAPK/JNK, Akt and p70 S6 kinase in MC3T3-E1 cells. Regarding the intracellular signaling of IGF-I in osteoblasts, our group previously demonstrated that $\mathrm{p} 44 / \mathrm{p} 42$ MAP kinase and Akt may serve as positive regulators in the IGF-I-stimulated activity of alkaline phosphatase, a biochemical marker of bone formation, in osteoblast-like MC3T3-E1 cells $(8,9)$. It is established that the MAP kinase superfamily including p44/p42 MAP kinase, p38 MAP kinase and SAPK/JNK are essential molecules in the transduction of various messages from a range of stimulators (26). As for osteoblast migration, it has been reported that the pathway of PI3K/Akt is involved in the IGF-I-stimulated migration (10). In addition, p70 S6 kinase is reportedly implicated in ovarian cancer cell 


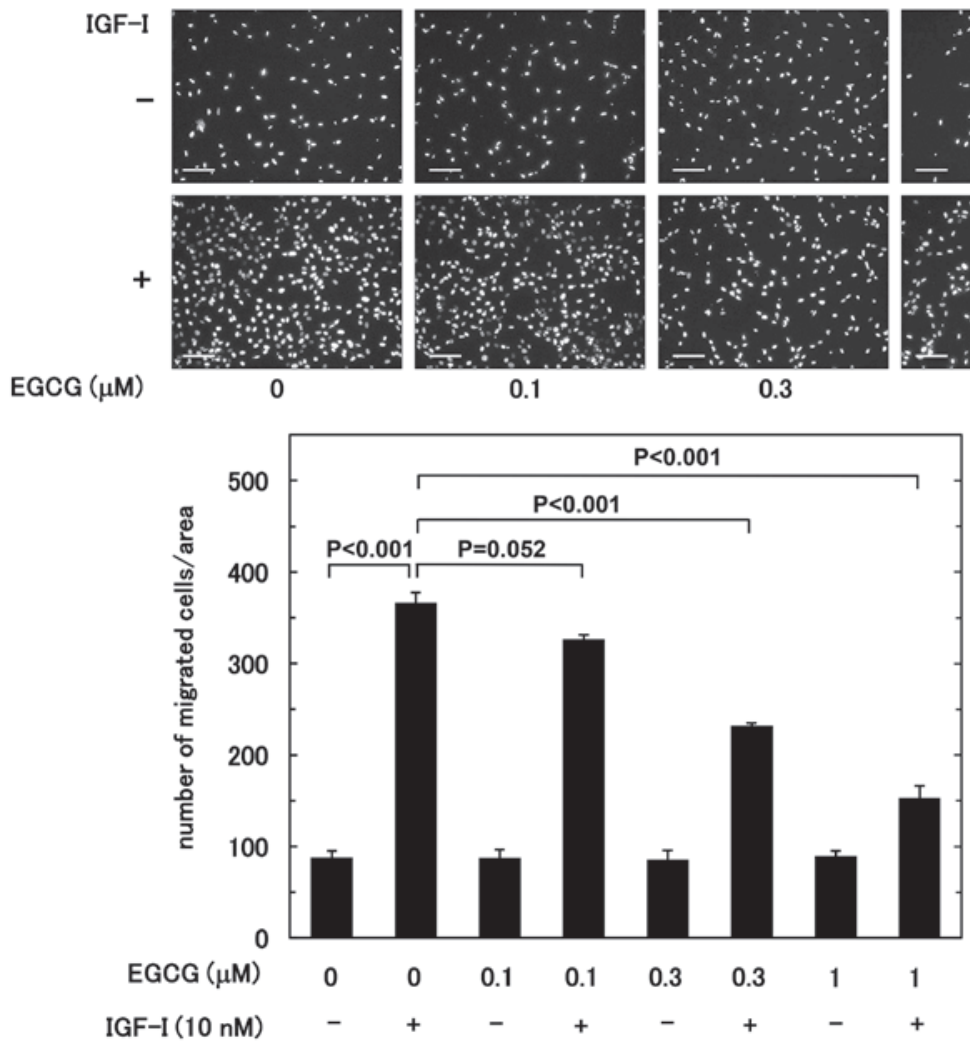

Figure 2. Effect of EGCG on IGF-I-induced migration of MC3T3-E1 cell. Cell migration was evaluated using a Boyden chamber. The cells were pretreated with various doses of EGCG for $60 \mathrm{~min}$, and then stimulated by $10 \mathrm{nM}$ IGF-I or vehicle for $16 \mathrm{~h}$. Photographs (white signal) and a histogram showing the numbers of migrated cells in each panel are presented. Magnification, x20; scale bars, $100 \mu \mathrm{m}$. EGCG, (-)-epigallocatechin gallate; IGF-I, insulin-like growth factor-I.

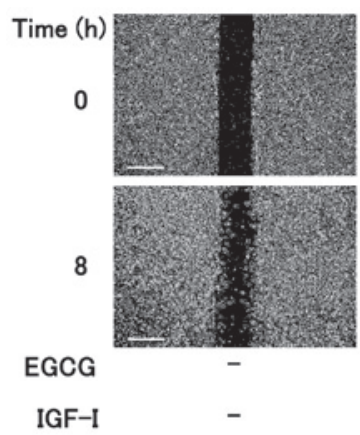

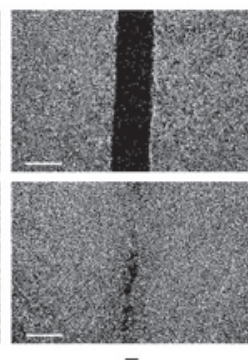

$-$

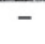

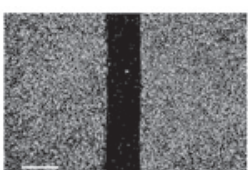
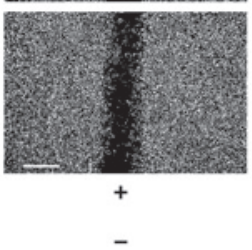

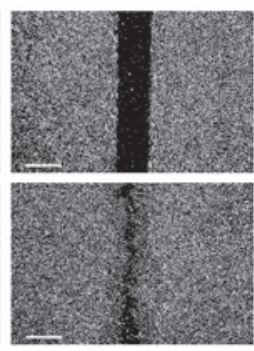

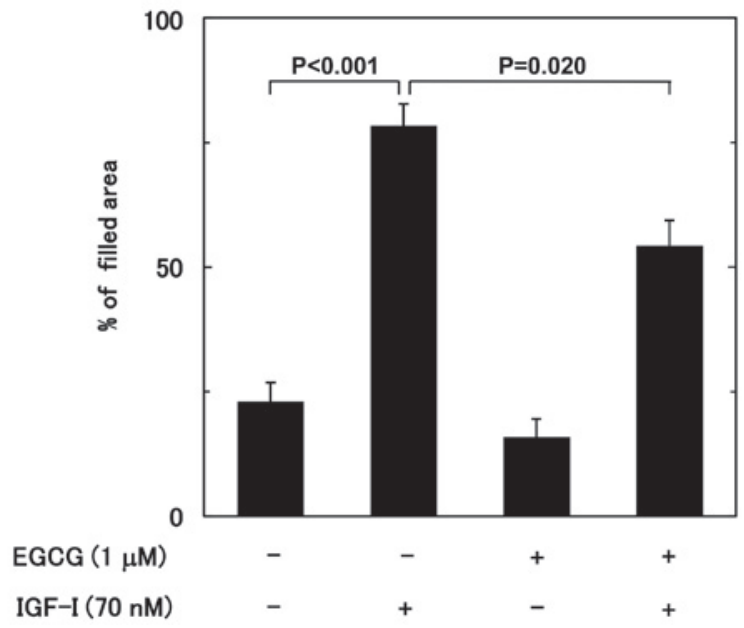

Figure 3. Effect of EGCG on IGF-I-induced migration of MC3T3-E1 cells. Cell migration was evaluated by a wound healing assay. The cells were pretreated with $1 \mu \mathrm{M}$ EGCG or vehicle for $60 \mathrm{~min}$, and then stimulated by $70 \mathrm{nM}$ IGF-I or vehicle for 8 h. The cells were photographed prior to IGF-I-stimulation ( 0 h) and after $8 \mathrm{~h}$, and the area of migrated cells was measured. Magnification, x10; scale bars, $500 \mu$ m. EGCG, (-)-epigallocatechin gallate; IGF-I, insulin-like growth factor-I. 


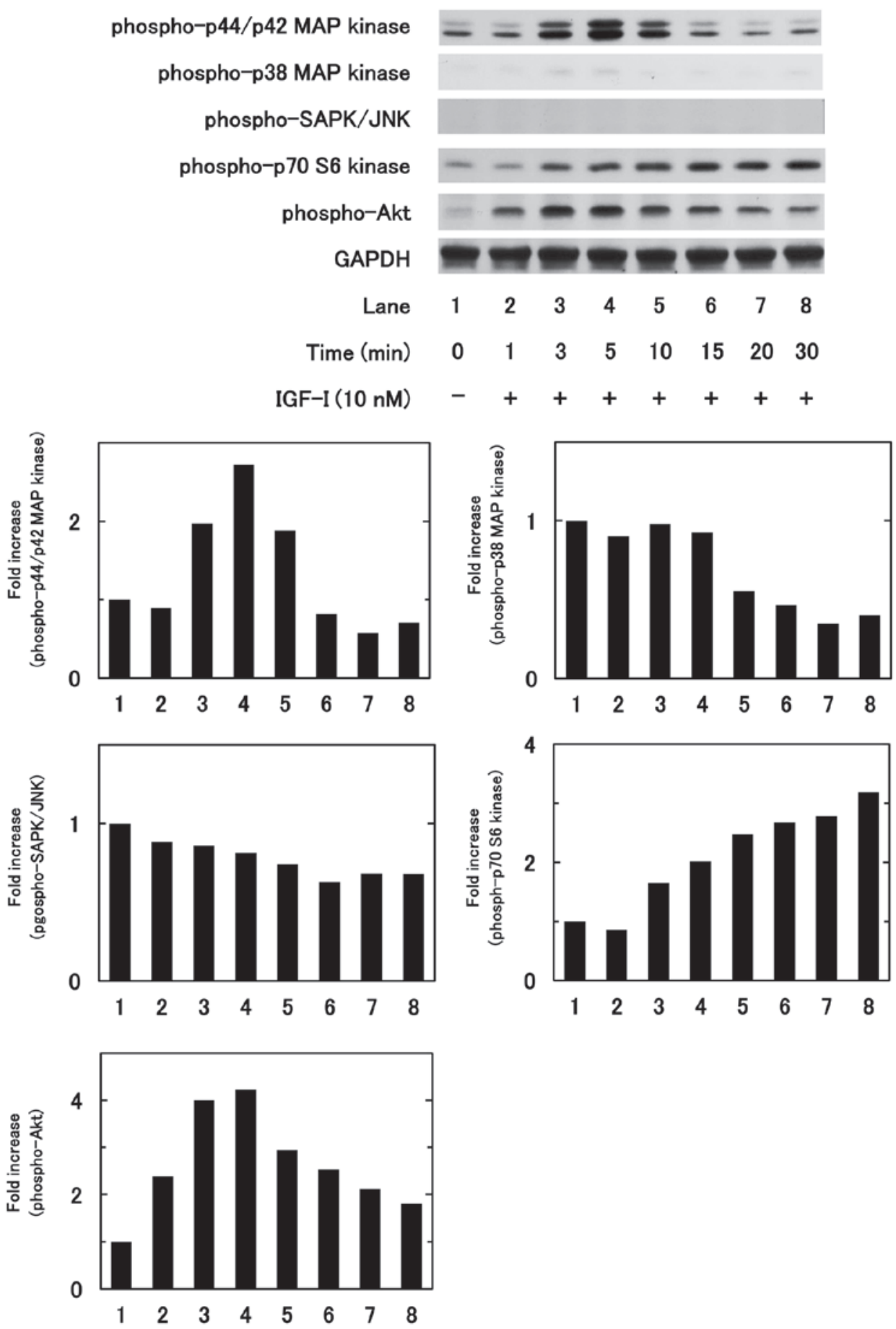

Figure 4. Effects of IGF-I on the phosphorylation of p44/p42 MAP kinase, p38 MAP kinase, SAPK/JNK, Akt and p70 S6 kinase in MC3T3-E1 cells. The cells were stimulated by $10 \mathrm{nM}$ IGF-I for the indicated periods. Western blot analysis was performed using antibodies against phospho-p44/p42 MAP kinase, phospho-p38 MAP kinase, phospho-SAPK/JNK, phospho-p70 S6 kinase, phospho-Akt and GAPDH. IGF-I, insulin-like growth factor-I; MAP, mitogen-activated protein; SAPK/JNK, stress-activated protein kinase/c-Jun N-terminal kinase.

migration (27). In the current study, the phosphorylation of p44/p42 MAP kinase, p70 S6 kinase and Akt was markedly induced by IGF-I (10 nM), while IGF-I had little effect on the phosphorylation of p38 MAP kinase and SAPK/JNK (Fig. 4), suggesting that IGF-I stimulates the activation of $\mathrm{p} 44 / \mathrm{p} 42$ MAP kinase, Akt and p70 S6 kinase but not of p38 MAP kinase and SAPK/JNK in osteoblast-like MC3T3-E1 cells. GAPDH was adopted as the control instead of p70 S6 kinase, since reliable antibodies against non-phosphorylated p70 S6 kinase were not obtained.
Effects of PD98059, rapamycin and deguelin on IGF-I-induced migration of MC3T3-E1 cells. To investigate whether p44/p42 MAP kinase, p70 S6 kinase or Akt is involved in the IGF-I-stimulated migration of osteoblast-like MC3T3-E1 cells, the effects of PD98059, an inhibitor of the upstream kinase that activates p44/p42 MAP kinase [MAP kinase kinase (MEK)1/2] (28), rapamycin, an inhibitor of mammalian target of rapamycin (mTOR) that activates p70 S6 kinase (29), and deguelin, an inhibitor of Akt (30) on the induced migration were assessed (Figs. 5-7). Treatment with PD98059 or deguelin 
A
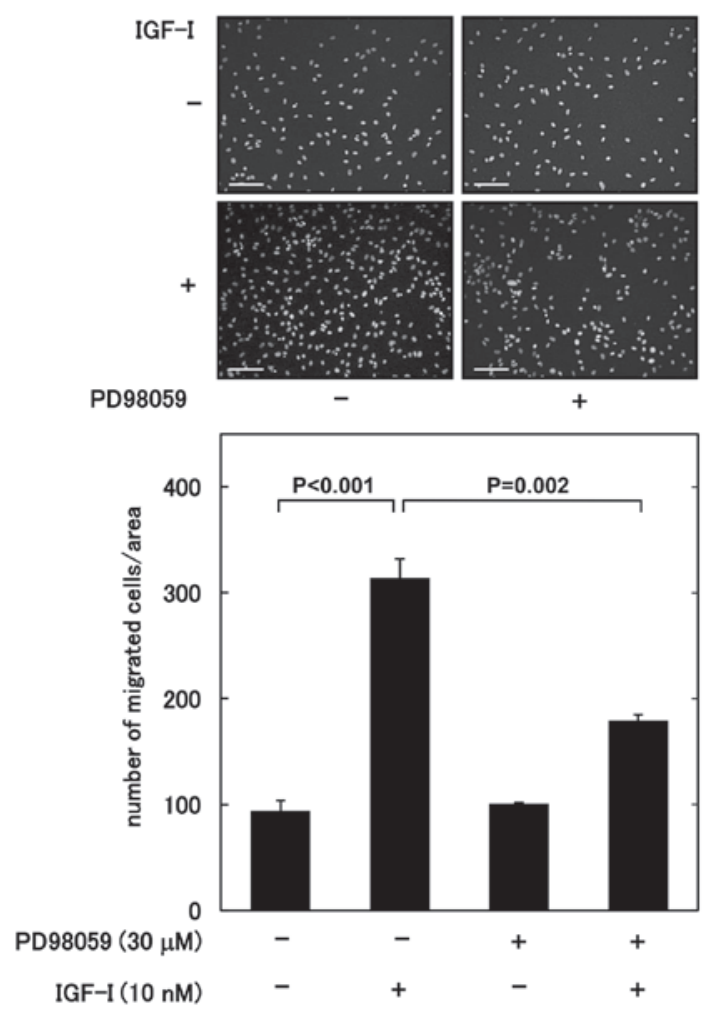

B
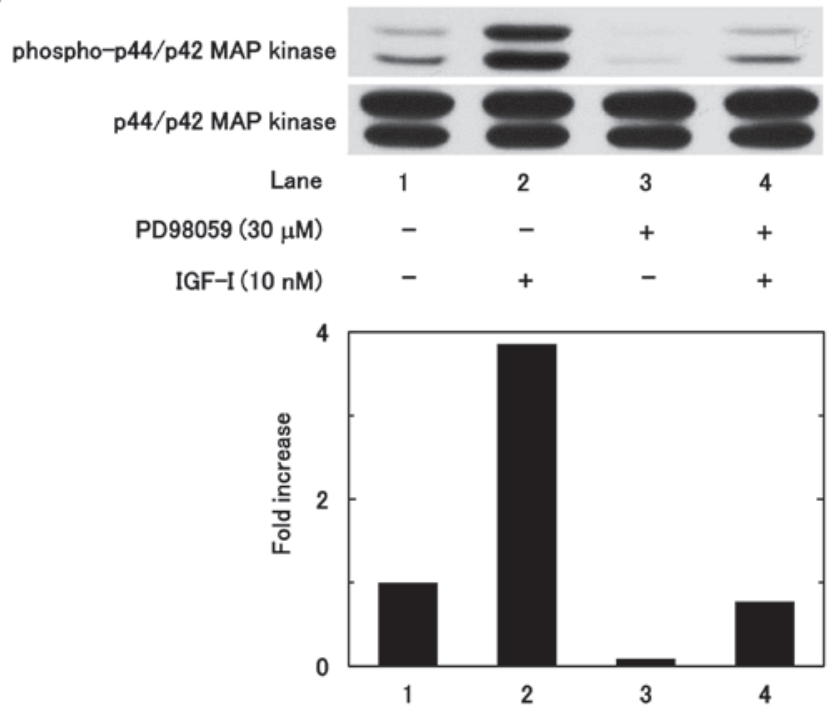

Figure 5. Effect of PD98059 on IGF-I-induced migration of MC3T3-E1 cells. (A) Cell migration was evaluated using a Boyden chamber. The cells were pretreated with $30 \mu \mathrm{M}$ PD98059 or vehicle for $60 \mathrm{~min}$, and then stimulated by $10 \mathrm{nM}$ IGF-I or vehicle for $16 \mathrm{~h}$. Photographs (white signal) and a histogram showing the numbers of migrated cells in each panel are presented. Magnification, x20; scale bars, $100 \mu \mathrm{m}$. (B) The cells were pretreated with $30 \mu \mathrm{M}$ of PD98059 or vehicle for $60 \mathrm{~min}$, and then stimulated by $10 \mathrm{nM}$ IGF-I or vehicle for $5 \mathrm{~min}$. Western blot analysis was performed using antibodies against phospho-p44/p42 MAP kinase or p44/p42 MAP kinase. IGF-I, insulin-like growth factor-I; MAP, mitogen-activated protein.

significantly reduced the IGF-I-induced migration $(\mathrm{P}=0.002$ and 0.014 , respectively) (Figs. 5A and 7A), whereas rapamycin did not affect the migration induced by IGF-I (Fig. 6A). It was confirmed that in MC3T3-E1 cells, PD98059, deguelin and rapamycin acted as an inhibitor of their respective targets (Figs. 5B, 6B and 7B).
A
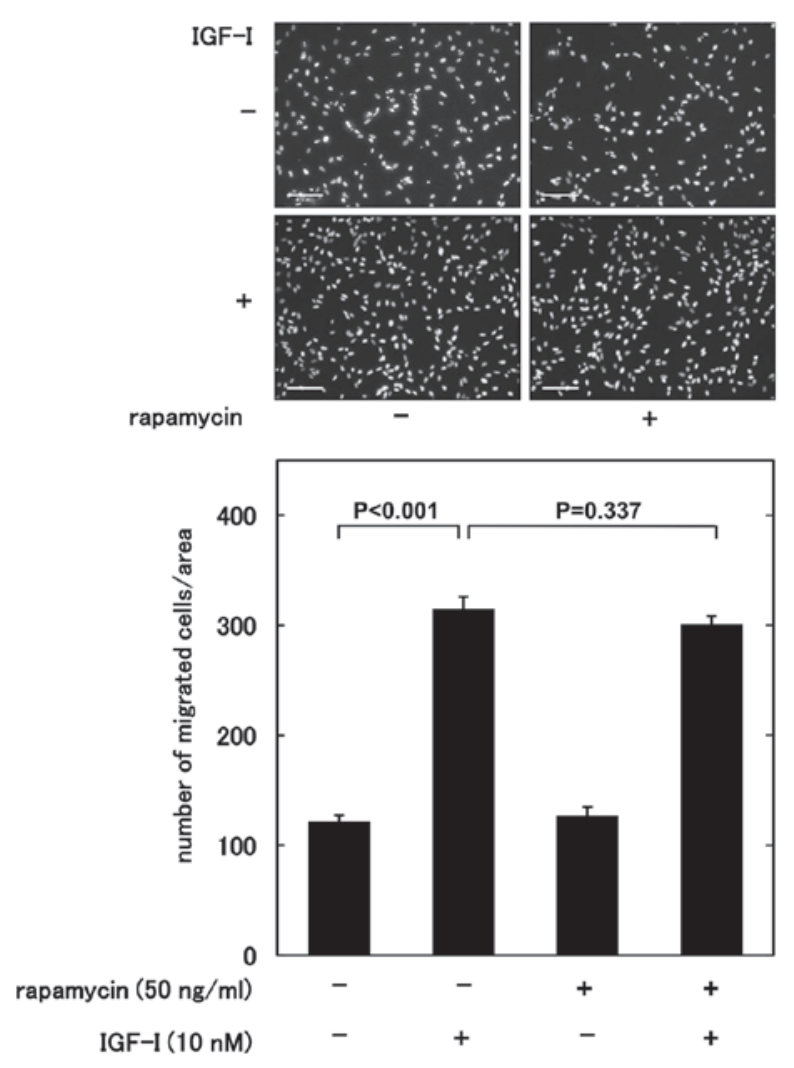

B
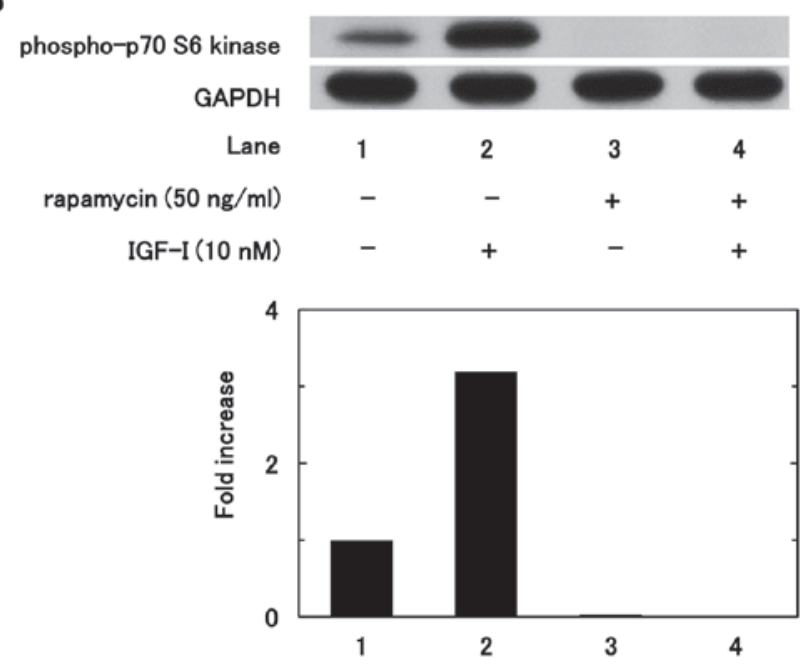

Figure 6. Effect of rapamycin on IGF-I-induced migration of MC3T3-E1 cells. (A) Cell migration was evaluated using a Boyden chamber. The cells were pretreated with $50 \mathrm{ng} / \mathrm{ml}$ rapamycin or vehicle for $60 \mathrm{~min}$, and then stimulated by $10 \mathrm{nM}$ IGF-I or vehicle for $16 \mathrm{~h}$. Photographs (white signal) and a histogram showing the numbers of migrated cells in each panel are presented. Magnification, x20; scale bars, $100 \mu \mathrm{m}$. (B) The cells were pretreated with $50 \mathrm{ng} / \mathrm{ml}$ rapamycin or vehicle for $60 \mathrm{~min}$, and then stimulated by $10 \mathrm{nM} \mathrm{IGF-I}$ or vehicle for $10 \mathrm{~min}$. Western blot analysis was performed using antibodies against phospho-p70 S6 kinase or GAPDH. IGF-I, insulin-like growth factor-I.

Effect of EGCG on IGF-I-induced phosphorylation of p $44 / p 42$ MAP kinase and Akt in MC3T3-El cells. To clarify the mechanism underlying the inhibition of IGF-I-induced migration by EGCG, the effect of EGCG on the IGF-I-induced phosphorylation of p44/p42 MAP kinase and Akt was investigated. EGCG (20 and $30 \mu \mathrm{M}$ ) significantly reduced the IGF-I-induced 
A

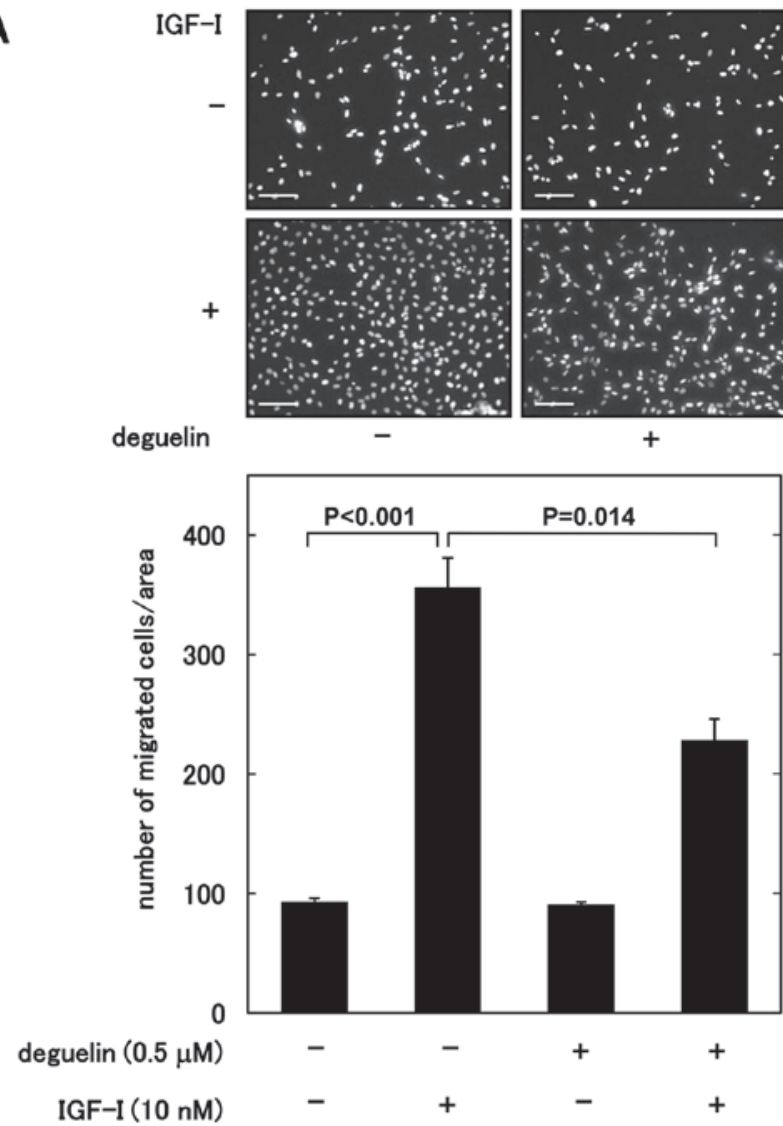

B
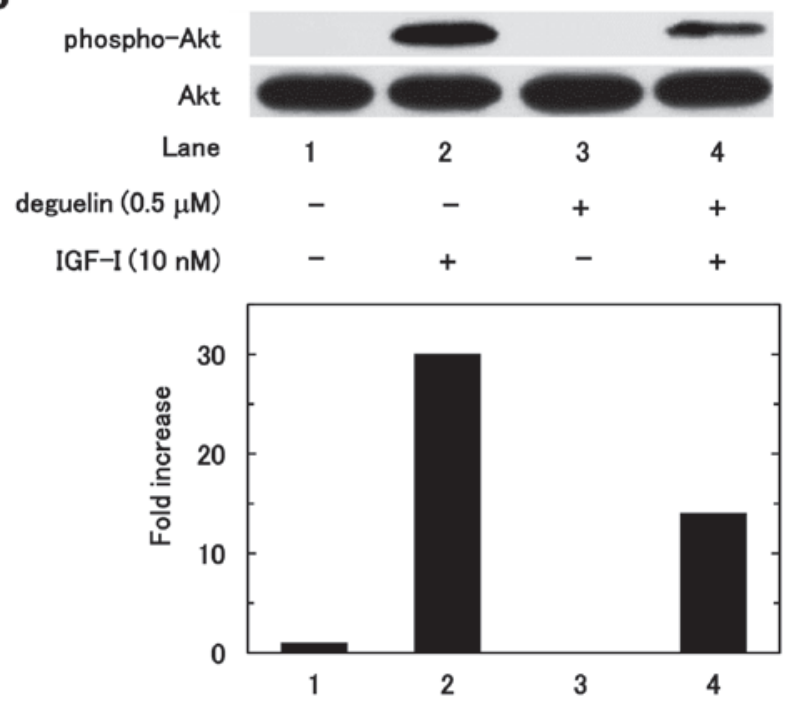

Figure 7. Effect of deguelin on IGF-I-induced migration of MC3T3-E1 cells. (A) Cell migration was evaluated using a Boyden chamber. The cells were pretreated with $0.5 \mu \mathrm{M}$ deguelin or vehicle for $60 \mathrm{~min}$, and then stimulated by $10 \mathrm{nM}$ IGF-I or vehicle for $16 \mathrm{~h}$. Photographs (white signal) and a histogram showing the numbers of migrated cells in each panel are presented. Magnification, $\mathrm{x} 20$; scale bars, $100 \mu \mathrm{m}$. (B) The cells were pretreated with $0.5 \mu \mathrm{M}$ deguelin or vehicle for $60 \mathrm{~min}$, and then stimulated by $10 \mathrm{nM}$ IGF-I or vehicle for $3 \mathrm{~min}$. Western blot analysis was performed using antibodies against phospho-specific Akt or Akt. IGF-I, insulin-like growth factor-I.

phosphorylation of p44/p42 MAP kinase (Fig. 8A); whereas the IGF-I-induced phosphorylation of Akt was not affected by EGCG (Fig. 8B).

\section{Discussion}

In the present study, it was demonstrated the IGF-I-induced migration of osteoblast-like MC3T3-E1 cells was significantly suppressed by EGCG, a major catechin in green tea $(14,18)$, whereas chlorogenic acid, a main polyphenol in coffee (13), did not affect the induced migration. The intracellular signaling system behind the IGF-I-induced migration of osteoblast-like MC3T3-E1 cells was also investigated, as well as the exact mechanism underlying the inhibition of IGF-I-induced migration by EGCG. The IGF-I-induced migration of MC3T3-E1 cells was suppressed by PD98059, an MEK inhibitor (28), and deguelin, an Akt inhibitor (30), in osteoblast-like MC3T3-E1 cells. Regarding the intracellular signaling of IGF-I in osteoblast migration, it has been reported that phosphatidylinositol 3-kinase is involved in the migration event (10). Since it is generally known that Akt acts at a point downstream of phosphatidylinositol 3-kinase, the current finding is consistent with that reported previously. Based on overall findings, it is probable that $\mathrm{p} 44 / \mathrm{p} 42$ MAP kinase and Akt serve as positive regulators in the IGF-I-induced migration of osteoblast-like MC3T3-E1 cells. In addition, it was identified that EGCG markedly reduced the IGF-I-induced phosphorylation of p44/p42 MAP kinase without affecting the induced phosphorylation of Akt in MC3T3-E1 cells. Collectively, these findings suggest that EGCG repressed the IGF-I-induced migration of osteoblast-like MC3T3-E1 cells through inhibition of p44/p42 MAP kinase.

In physiological bone remodeling, the migration of osteoblasts to the sites resorbed by osteoclasts is an essential step, as the migrated osteoblasts are activated and initiate bone formation at the bone resorbed sites, resulting in the maintenance of moderate bone mass (3-5). In addition, the migration of osteoblasts is crucial also in the case of pathological bone states including osteoporosis and bone fracture repair (3-5). Thus, appropriate migration of osteoblasts is necessary for the regulation of bone remodeling, and proper osteoblast migration is considered to be essential for maintaining both the quantity and quality of bone mass $(1,3-5)$. It has been proposed that green tea consumption may be associated with increased bone mass, improved bone density and decreased risk of bone fracture (18). Green tea polyphenols including EGCG reportedly protected bone loss in middle-aged female rats following ovariectomy in vivo (31). It has also been reported that lower concentrations $(1,5$ and $10 \mu \mathrm{M})$ of EGCG did not affect the migration of alveolar bone cells, whereas higher concentrations (25 and $50 \mu \mathrm{M}$ ) suppressed cell migration analyzed by wound-healing assay (32). In the present study, the significant suppressive effect of EGCG on the IGF-I-induced migration of MC3T3-E1 cells was observed at $1 \mu \mathrm{M}$ in Transwell and wound healing assays. Based on these findings, it is possible that EGCG elicits a modulatory effect in osteoblast migration, leading to appropriate bone remodeling. It has been documented that the maximum plasma concentration of EGCG reaches approximately $0.7 \mu \mathrm{M}$ following moderate green tea ingestion (3 g decaffeinated green tea solids) in humans (33). Regarding chlorogenic acid, it has been reported that when single servings of coffee beverage containing low (412 $\mu \mathrm{mol})$, medium $(635 \mu \mathrm{mol})$ and high $(795 \mu \mathrm{mol})$ levels of chlorogenic acids were administered to healthy subjects, a value of maximum peak 
A
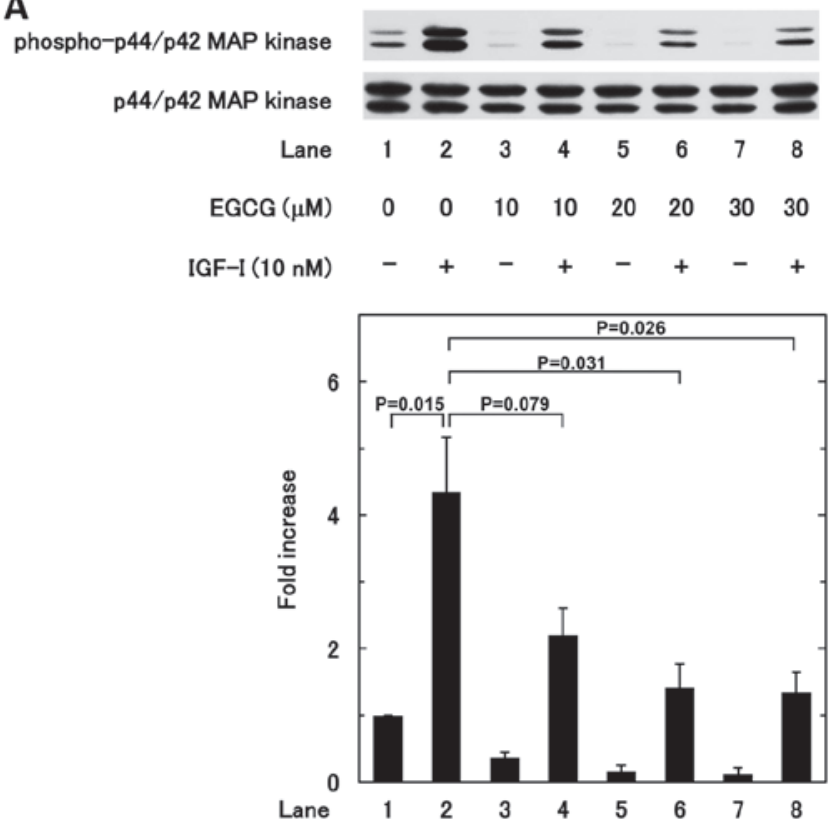

B
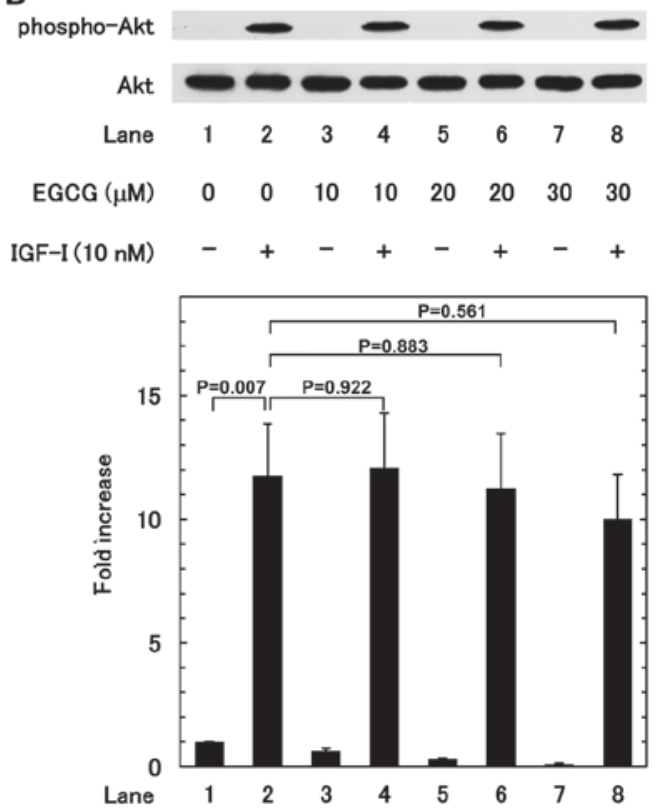

Figure 8. Effects of EGCG on IGF-I-induced phosphorylation of (A) p44/p42 MAP kinase and (B) Akt in MC3T3-E1 cells. The cells were pretreated with various doses of EGCG for $60 \mathrm{~min}$, and then stimulated by $10 \mathrm{nM}$ IGF-I or vehicle for (A) $5 \mathrm{~min}$ or (B) 3 min. Western blot analysis was performed using antibodies against phospho-p44/p42 MAP kinase, p44/p42 MAP kinase, phospho-Akt and Akt. The histograms show quantitative representation of the levels of IGF-I-induced phosphorylation determined from laser densitometric analysis of three independent experiments. EGCG, (-)-epigallocatechin gallate; IGF-I, insulin-like growth factor-I; MAP, mitogen-activated protein.

plasma concentration of approximately $1.5 \mu \mathrm{M}$ was observed in following the medium level serving (34), which is considerably lower than the doses used in the present study. Taking these findings into account, the concentrations of EGCG and chlorogenic acid used for osteoblast migration in vitro in the present study appeared physiologically relevant to green tea drinkers but rather super-physiological to coffee consumers in vivo. In addition, it has been reported that IGF-I upregulates osteoclastogenesis from monocytes in vitro (35). Thus, it is possible that IGF-I can potentiate the osteoclast supply in the process of bone remodeling in addition to stimulating osteoblast migration. In the present study, the effects of EGCG and chlorogenic acid were elucidated only with regard to osteoblast-like MC3T3-E1 cells, and not monocyte-osteoclast lineage cells. To understand the exact mechanism underlying the potential favorable effects of natural compounds including EGCG and chlorogenic acid on human bone health and protection against osteoporosis, experiments in monocyte-osteoclast lineage cells in addition to osteoblasts would be useful. Further investigations are also required to clarify the molecular mechanism underlying the apparent inhibition of IGF-I-induced osteoblast migration by EGCG.

In conclusion, the present results suggest that EGCG represses IGF-I-induced migration of osteoblasts, possibly resulting in the adjustment of bone remodeling, and that the effect of EGCG is exerted through the suppression of p44/p42 MAP kinase.

\section{Acknowledgements}

The authors are thankful to Mrs. Yumiko Kurokawa (Department of Pharmacology, Gifu University Graduate School of Medicine, Gifu, Japan) for her technical assistance.

\section{Funding}

The current investigation was supported in part by Grantsin-Aid for Scientific Research (grant nos. 26462289 and 15K10487) from the Ministry of Education, Culture, Sports, Science and Technology of Japan, a Grant-in-Aid for Scientific Research (grant no. H25-Aging-General-004) from the Ministry of Health, Labour and Welfare of Japan, and Research Funding for Longevity Sciences (grant nos. 26-12 and 28-9) from the National Center for Geriatrics and Gerontology, Japan.

\section{Availability of data and materials}

The datasets used and/or analyzed during the current study are available from the corresponding author on reasonable request.

\section{Authors' contributions}

TK, TO and OK conceived and designed the experiments. TK, GS, KF, and RM-N performed the experiments. TK, GS, KF, RM-N, HT and OK analyzed the data. TK, TO, HT and OK wrote the manuscript. All authors read and approved the final manuscript.

\section{Ethics approval and consent to participate}

Not applicable.

\section{Consent for publication}

Not applicable. 


\section{Competing interests}

The authors declare that they have no competing interests.

\section{References}

1. Karsenty G and Wagner EF: Reaching a genetic and molecular understanding of skeletal development. Dev Cell 2: 389-406, 2002.

2. Kular J, Tickner J, Chim SM and Xu J: An overview of the regulation of bone remodelling at the cellular level. Clin Biochem 45: 863-873, 2012.

3. Khan SN, Bostrom MP and Lane JM: Bone growth factors. Orthop Clin North Am 31: 375-388, 2000.

4. Lieberman JR, Daluiski A and Einhorn TA: The role of growth factors in the repair of bone. Biology and clinical applications. J Bone Joint Surg Am 84-A: 1032-1044, 2002.

5. Reddi AH, Roodman D, Freeman C and Mohla S: Mechanisms of tumor metastasis to the bone: Challenges and opportunities. J Bone Miner Res 18: 190-194, 2003.

6. Clemens TL and Chernausek SD: Genetic strategies for elucidating insulin-like growth factor action in bone. Growth Horm IGF Res 14: 195-199, 2004.

7. Niu $\mathrm{T}$ and Rosen CJ: The insulin-like growth factor-I gene and osteoporosis: A critical appraisal. Gene 361: 38-56, 2005.

8. Noda T, Tokuda H, Yoshida M, Yasuda E, Hanai Y, Takai S and Kozawa O: Possible involvement of phosphatidylinositol 3-kinase/Akt pathway in insulin-like growth factor-I-induced alkaline phosphatase activity in osteoblasts. Horm Metab Res 37: 270-274, 2005

9. Hanai Y, Tokuda H, Ishisaki A, Matsushima-Nishiwaki R, Nakamura N, Yoshida M, Takai S, Ohta T and Kozawa O: Involvement of p44/p42 MAP kinase in insulin-like growth factor-I-induced alkaline phosphatase activity in osteoblastlike-MC3T3-E1 cells. Mol Cell Endocrinol 251: 42-48, 2006.

10. Nakasaki M, Yoshioka K, Miyamoto Y, Sasaki T, Yoshikawa H and Itoh K: IGF-I secreted by osteoblasts acts as a potent chemotactic factor for osteoblasts. Bone 43: 869-879, 2008.

11. Jankun J, Selman SH, Swiercz R and Skrzypczak-Jankun E: Why drinking green tea could prevent cancer. Nature 387: 561, 1997.

12. Koo SH and Montminy M: In vino veritas: A tale of two sirtls? Cell 127: 1091-1093, 2006.

13. George SE, Ramalakshmi K and Mohan Rao LJ: A perception on health benefits of coffee. Crit Rev Food Sci Nutr 48: 464-486, 2008.

14. Thielecke F and Boschmann M: The potential role of green tea catechins in the prevention of the metabolic syndrome - a review. Phytochemistry 70: 11-24, 2009.

15. Shimizu M, Adachi S, Masuda M, Kozawa O and Moriwaki H: Cancer chemoprevention with green tea catechins by targeting receptor tyrosine kinases. Mol Nutr Food Res 55: 832-843, 2011.

16. Folwarczna J, Pytlik M, Zych M, Cegieła U, Nowinska B, Kaczmarczyk-Sedlak I, Sliwinski L, Trzeciak H and Trzeciak HI: Effects of caffeic and chlorogenic acids on the rat skeletal system. Eur Rev Med Pharmacol Sci 19: 682-693, 2015.

17. Kwak SC, Lee C, Kim JY, Oh HM, So HS, Lee MS, Rho MC and Oh J: Chlorogenic acid inhibits osteoclast differentiation and bone resorption by down-regulation of receptor activator of nuclear factor $\kappa-\mathrm{B}$ ligand-induced nuclear factor of activated T cells c1 expression. Biol Pharm Bull 36: 1779-1786, 2013.

18. Shen CL, Yeh JK, Cao JJ and Wang JS: Green tea and bone metabolism. Nutr Res 29: 437-456, 2009.
19. Singh R, Akhtar N and Haqqi TM: Green tea polyphenol epigallocatechin-3-gallate: Inflammation and arthritis. [corrected]. Life Sci 86: 907-918, 2010.

20. Fujita K, Otsuka T, Yamamoto N, Kainuma S, Ohguchi R, Kawabata T, Sakai G, Kuroyanagi G, Matsushima-Nishiwaki R, Kozawa O, et al: (-)-Epigallocatechin gallate but not chlorogenic acid upregulates osteoprotegerin synthesis through regulation of bone morphogenetic protein-4 in osteoblasts. Exp Ther Med 14: 417-423, 2017.

21. Sudo H, Kodama HA, Amagai Y, Yamamoto S and Kasai S: In vitro differentiation and calcification in a new clonal osteogenic cell line derived from newborn mouse calvaria. J Cell Biol 96: 191-198, 1983.

22. Kozawa O, Tokuda H, Miwa M, Kotoyori J and Oiso Y: Cross-talk regulation between cyclic AMP production and phosphoinositide hydrolysis induced by prostaglandin E2 in osteoblast-like cells. Exp Cell Res 198: 130-134, 1992.

23. Karagiosis SA, Chrisler WB, Bollinger N and Karin NJ: Lysophosphatidic acid-induced ERK activation and chemotaxis in MC3T3-E1 preosteoblasts are independent of EGF receptor transactivation. J Cell Physiol 219: 716-723, 2009.

24. Laemmli UK: Cleavage of structural proteins during the assembly of the head of bacteriophage T4. Nature 227: 680-685, 1970.

25. Kato K, Ito H, Hasegawa K, Inaguma $\mathrm{Y}$, Kozawa $\mathrm{O}$ and Asano T: Modulation of the stress-induced synthesis of hsp27 and alpha B-crystallin by cyclic AMP in C6 rat glioma cells. J Neurochem 66: 946-950, 1996.

26. Kyriakis JM and Avruch J: Mammalian MAPK signal transduction pathways activated by stress and inflammation: A 10-year update. Physiol Rev 92: 689-737, 2012.

27. Ip CK, Cheung AN, Ngan HY and Wong AS: p70 S6 kinase in the control of actin cytoskeleton dynamics and directed migration of ovarian cancer cells. Oncogene 30: 2420-2432, 2011.

28. Alessi DR, Cuenda A, Cohen P, Dudley DT and Saltiel AR: PD 098059 is a specific inhibitor of the activation of mitogen-activated protein kinase kinase in vitro and in vivo. J Biol Chem 270: 27489-27494, 1995.

29. Li Y, Corradetti MN, Inoki K and Guan KL: TSC2: Filling the GAP in the mTOR signaling pathway. Trends Biochem Sci 29: 32-38, 2004.

30. Toker A and Newton AC: Cellular signaling: Pivoting around PDK-1. Cell 103: 185-188, 2000.

31. Shen CL, Wang P, Guerrieri J, Yeh JK and Wang JS: Protective effect of green tea polyphenols on bone loss in middle-aged female rats. Osteoporos Int 19: 979-990, 2008.

32. Mah YJ, Song JS, Kim SO, Lee JH, Jeon M, Jung UW, Moon SJ, Kim JH and Choi HJ: The effect of epigallocatechin-3-gallate (EGCG) on human alveolar bone cells both in vitro and in vivo. Arch Oral Biol 59: 539-549, 2014.

33. Yang CS, Chen L, Lee MJ, Balentine D, Kuo MC and Schantz SP: Blood and urine levels of tea catechins after ingestion of different amounts of green tea by human volunteers. Cancer Epidemiol Biomarkers Prev 7: 351-354, 1998.

34. Stalmach A, Williamson G and Crozier A: Impact of dose on the bioavailability of coffee chlorogenic acids in humans. Food Funct 5: 1727-1737, 2014.

35. Zhu Z, Huang P, Chong Y, George SK, Wen B, Han N, Liu Z, Kang L and Lin N: Nucleus pulposus cells derived IGF-1 and MCP-1 enhance osteoclastogenesis and vertebrae disruption in lumbar disc herniation. Int J Clin Exp Pathol 7: 8520-8531, 2014. 